\title{
Más Allá de Velos y PEINAdos: LAS REELABORACIONES ÉTNICAS Y GENÉRICAS DE LAS CHAMULAS musulmanas sufis en San Cristóbal de Las Casas
}

\author{
Angélica Schenerock
}

$\mathrm{E}$ 1 tema de la religiosidad con sus subjetividades, en especial aquellas que se refieren a los cam bios y conversiones religiosas de mujeres y hombres, ha presentado de cierta manera un desafío a las ciencias sociales por tratarse de un ámbito del saber en el cual el tradicional discurso objetivo y unidisciplinar se vuelve insuficiente para una comprensión más abarcadora. Seyyed Hossein Nasr, profesor del Departamento de Estudios Islámicos de la Universidad George Washington argumenta que "pocos estudiosos de las religiones, tanto en Occidente y aun en el Oriente moderno, pueden comprender la religiosidad, particularmente la noción de lo sagrado en distintas creencias, porque invariablemente interpretan estos conceptos a través del historicismo, y el cientificismo, reduciendo irremediablemente con ello lo sagrado a lo profano" (Ederly y Argüelles, 2003: 24).

Comparto este punto de vista, pues pienso que para reflexionar sobre los posibles cambios y reelaboraciones étnicas y genéricas de las mujeres tzotziles originarias del municipio de San Juan Chamula que migraron a San Cristóbal de Las Casas y hoy hacen parte de la comunidad musulmana sufi de San Cristóbal de Las Casas, se vuelven necesarios otros acercamientos teó-

Angélica Schenerock, alumna de la maestría en Ciencias Sociales con opción en Estudios Fronterizos del CESMECA-UNICACH. Este artículo es un resumen de su tesis de maestría. ricos que den cuenta de una realidad compleja en donde se fusionan género, identidad étnica y religión. No existe una teoría única que nos permita realizar una investigación científica sobre estos tres problemas. $\mathrm{Al}$ contrario, un análisis como este requiere de diversas teorías, algunas de ellas elaboradas como parte de paradigmas de otras disciplinas, pero que unidas en una postura dialógica, nos aportarán las herramientas necesarias para dar cuenta del problema de las identidades étnicas y genéricas de las mujeres chamulas que hacen parte de la comunidad musulmana sufi de San Cristóbal de Las Casas de una forma más dinámica, inclusiva y flexible.

Comprendo la religión como una de las esferas de la vida cotidiana, pues la relación con lo sagrado, con lo sobrenatural, proporciona el encuentro con el sentido que se da a las alegrías y sufrimientos del día a día, a los encuentros y desencuentros, a la enfermedad y a la salud, al nacimiento y la muerte. La búsqueda de sentido y de mejores condiciones de vida por medio de la religión es un hecho cotidiano para muchas personas.

Teniendo en cuenta la compleja realidad cotidiana en la cual estamos inmersas e inmersos, pienso que una forma de abordar los cambios étnicos y genéricos de las mujeres indígenas musulmanas es la de abordarla en 
un enfoque interdisciplinar. Como es sabido, la interdisciplinariedad va mucho más allá del "poner en contacto" los discursos de diferentes disciplinas, al contrario, busca alcanzar un discurso común entre ellas (Agazzi, 2002: 1). Conforme Evandro Agazzi, la interdisciplina ofrece un camino para superar las tan comunes fragmentaciones del saber, y realizar una unidad del mismo, tomando en cuenta la complejidad de las realidades que nos rodean (Idem: 2). Para el autor, el principal desafío de la interdisciplina consiste, "por un lado, el tomar como punto de partida las diferentes disciplinas, respetando su especificidad de conceptos, métodos y lógicas y, por otro lado, trabajar para que todo ello no resulte una 'barrera' para la comunicación”" (Idem: 3).

En el caso específico de los cambios y reelaboraciones étnicas y genéricas de las indígenas chamulas que hacen parte de la comunidad musulmana sufi de San Cristóbal de Las Casas, se vuelve útil el diálogo entre las ciencias sociales y la teología. Esto, porque las investigaciones que hacen algunas de las ciencias sociales, en este caso la sociología y la antropología de la religión, pueden ser enriquecidas con la teología cuando nos preguntamos sobre los aspectos subjetivos de estos comportamientos, sobre la dimensión de la fe, sobre la génesis o necesidad de tener un Dios en quien confiar, un dogma y un sistema de símbolos normativos de la vida cotidiana, una comunidad de fe en la cual compartir los acontecimientos cotidianos y fortalecer la fe.

Entiendo como teología el estudio sistematizado de las relaciones y pensamientos de los seres humanos sobre Dios, y las acciones que se desprenden de este pensamiento. El objeto principal de la teología, por lo tanto, no es probar la existencia de Dios (ya que esto, además de ser el presupuesto de la teología, no se puede comprobar), sino, en pocas palabras, reflexionar y discernir sobre las imágenes de Dios en el transcurso de la historia y vida humanas.
Convocar a una disciplina como la teología para dialogar con las ciencias sociales sobre los cambios y reelaboraciones étnicas y genéricas de las mujeres chamulas que hacen parte de la comunidad musulmana sufide San Cristóbal de Las Casas puede ser considerado científicamente heterodoxo para las mentes más ocupadas con los serios e importantes factores económicos y políticos, además de sociales, que para aquellas motivadas a estudiar los cambios de religión y relaciones con lo sagrado y el poder ideológico de la fe y los textos sagrados.

Este poder ideológico de la fe y los textos sagrados, es rescatado en las ciencias sociales por Clifford Geertz y se une al enfoque teológico. Por ejemplo, la definición de religión propuesta por Geertz $z^{1}$ contribuye a enriquecer la comprensión fenomenológica de la religión y abre sus horizontes hacia la importancia de los símbolos. Al considerar la religión como un sistema de símbolos, Geertz apunta a su plano concreto e histórico, como parte de los esquemas culturales, que funcionan como "procesos sociales y psicológicos que modelan la conducta pública (Geertz, 1995: 91).

Por medio de la antropología interpretativa o simbólica, Geertz nos ayuda a comprender que la religión es "en parte un intento (de una especie implícita y directamente sentida, antes que explícita y conscientemente pensada) de conservar el caudal de significaciones generales en virtud de las cuales cada individuo interpreta su experiencia y organiza su conducta" (Geertz, 1995: 118). La importancia de la religión está en "servir, para un individuo o para un grupo, como fuente de concepciones generales aunque distintivas, del mundo, del yo y de las relaciones entre sî" (Idem: 116). A través de sus símbolos, la religión permite a un grupo o sociedad sintetizar lo que se sabe sobre la vida y sus acontecimientos cotidianos, así como comprender sus sentimientos, esperanzas, miedos, victorias y fracasos. Y esta comprensión antropológica de la religión es compartida por la teología. Así, lejos de estar en conflicto, observo que estas disciplinas pueden complementarse de manera 
dialógica e incluyentes. Esta complementación la veo, además de en Geertz, en los trabajos de Peter Bergery Thomas Luckmann (1969).

Relacionado a lo anterior, tenemos que lo que ocurre a nivel histórico y concreto en nuestra vida está íntimamente ligado con aquello que pensamos, sentimos y creemos sobre ella, el mundo y los seres humanos. Cuando Geertz afirma que "no es el mundo exterior de los reinos y potencias lo que suministra el marco principal de la acción humana, sino que es el mundo interior de los sentimientos y deseos (Idem: 124), está rescatando la importancia de lo emocional y subjetivo en el quehacer de la antropología, que es algo muy común a la teología.

Jorge Ederly y Lourdes Argüelles sostienen la importancia del diálogo de las ciencias sociales con la teología para una comprensión más abarcadora de los fenómenos religiosos. Tomando como punto de partida los atentados en EUA el 11 de septiembre de 2001, estos investigadores se preguntan si el silencio en relación al fenómeno religioso en este día "no se debe a que es un golpe más para el positivismo. O si se deba quizá a que muchos intelectuales en Occidente se niegan a creer que exista gente que actúe motivada principalmente por razones religiosas, por más bizarras que éstas parezcan” (Ederly y Argüelles, 2002: 106). Los autores reivindican, en sus análisis, al factor religioso como un "sustrato insoslayable" cuando las disciplinas sociales ya no pueden dar cuenta de fenómenos complejos en los cuales está presente alguna manifestación de identidad religiosa.

Sabemos que la identidad religiosa está íntimamente relacionada con la experiencia religiosa, que consiste en un componente fundamental y central de los fenómenos religiosos y se revela por medio de los sistemas de creencias y de prácticas religiosas. Todos los fenómenos religiosos implican la relación de las personas fieles con una realidad que consideran superior. Se trata de la vivencia del mundo de lo sobrehumano por las personas religiosas. Esta vivencia es entendida por la fenomenología de la religión como un sentimiento y una creencia que experimentamos desde nuestra subjetividad, por ejemplo, la creencia y sentimientos hacia un ser o fuerza superior, sobrehumano; un sentimiento de lo sagrado frente al misterio, la grandeza y fragilidad de la vida en sus acontecimientos cotidianos y sus relaciones.

Desde el punto de vista histórico y concreto, la fenomenología considera la religión como manifestaciones locales históricas, concretas y específicas (Gallindo, 2001: 771), cuyos conjuntos de ritos, símbolos, doctrinas, dogmas, textos, reglas y normas prescriptivas de conducta, buscan dar forma, cuerpo y orden al punto de vista abstracto del sentimiento de lo sagrado. Tenemos aquí el ejemplo del judaísmo, del cristianismo, del Islam, del hinduismo, del budismo y el taoísmo, sólo para citar las más conocidas y antiguas especificaciones históricas de la religión.

Estas definiciones me parecen importantes cuando vamos a hablar sobre el Islam y sobre las mujeres indígenas chamulas que ahora hacen parte de la comunidad musulmana sufi de San Cristóbal de Las Casas, pues nos ayudan a ubicamos en el contexto religioso de la propia fe y experiencia religiosa de ellas.

Para empezar, el Islam trata, como sabemos, no solamente de una religión, sino de una civilización que surgió hace 15 siglos con el profeta Mahoma en la península arábiga y de ahí se propagó a diferentes partes del mundo, tanto oriental como occidental. La forma en que se vive, cree, interpreta y aplica el Islam varía de un lugar a otro: de la península arábiga al norte de África, por un lado, de Asia a Indonesia por otro lado y de Europa a América. Cada una de estas regiones con sus culturas ha asimilado e interpretado el Islam de acuerdo con sus peculiaridades específicas. Podemos decir, además, que el Islam trae en su seno una flexibilidad y una forma creativa de adaptabilidad a diferentes culturas. 
Esta complejidad y diversidad de formas de vivir e interpretar el Islam nos permite observar que delimitar una sola cultura musulmana y en extensión una sola forma de vivir e interpretar el Islam no sólo es imposible, sino también inadecuado. El mosaico cultural del Islam nos desafía a discernir los problemas inherentes a cada cultura y aquellos específicos de la religión musulmana, que a la vez marcan las pautas de cómo se practica y se cree en el Islam como religión y cultura. Tener esta diversidad en cuenta nos ayuda a evitar el error (común, infelizmente) de ver el Islam como un bloque único y monolítico. Cada país o región interpreta el Islam de acuerdo con sus particularidades y, en extensión, vive los ritos, la experiencia religiosa y la relación entre los sexos de acuerdo con estas particularidades.

Dado que este artículo se refiere a unas formas en que un grupo de mujeres chamulas ${ }^{2}$ que han migrado a San Cristóbal de Las Casas o son descendientes de las familias que fueron expulsadas del municipio y parajes de San Juan Chamula en diferentes ocasiones a partir de la década de los setenta, y ahora se han sumado al Is$\mathrm{lam}^{3}$, me parece importante hacer un pequeño recuento de cómo era el Islam en relación a las mujeres en los tiempos del profeta Mahoma.

\section{E1 Islam y las mujeres}

Tal como las demás regiones del Oriente $\mathrm{Medio}^{4}$, la Arabia preislámica compartía, en algunos aspectos muy generales, los prejuicios y tabúes relacionados con la mujer y su sexualidad, hecho que le quitaba a la gran mayoría de las mujeres (no todas, esto es muy importante) sus derechos a la propiedad y herencia, lo que las hacía no solamente dependientes del hombre, sino que fueran vistas y comprendidas como su propiedad; el hombre también podía "heredar" las mujeres en caso de que su "dueño" (padre, hermano, tío, abuelo, primo, señor) y muriera.
El noveno mandamiento judeo-cristiano ha tornado esta práctica de considerar a la mujer en aquellos tiempos como un objeto a poseer y heredar como cualquier otro: "No codicies la casa de tu prójimo. No codicies su mujer, ni sus servidores, su buey o su burro. No codicies nada de lo que le pertenece" (Éxodo 20.17). La mujer en estos casos era como un "bien" que el hombre poseía, podía heredar, comprar o vender como cualquier otro.

Es importante tener en cuenta que los pueblos semitas primitivos conferían un carácter sagrado a todo lo que se referiera al nacimiento y a las relaciones sexuales, de ahí que prescribieran leyes que regulaban estas prácticas y momentos de la vida, tal como las "leyes referentes a la pureza e impureza", nuevamente citando las fuentes judaicas del libro bíblico de Levítico (capítulos 11 al 15).

Vale la pena recordar que, para los judíos y las demás culturas semitas, lo "impuro" no quiere decir "sucio”, sino algo que está apartado del uso divino. Al contrario de lo que mucha gente piensa, la sexualidad y las relaciones sexuales no eran vistas como sucias o causa de pecado. ${ }^{5}$ Sin embargo, con el pasar del tiempo, estas leyes, originalmente formuladas como medida de control e higiene, se volvieron normativas para las relaciones desiguales entre los sexos, siendo que el cuerpo de la mujer, capaz de gestar, parir, amamantar y menstruar se volvió el cuerpo controlado en los diferentes aspectos de su vida civil: hija de, esposa de, viuda de...; laboral: trabajo doméstico, controlado en la casa; legal: no tiene derecho de repudiar al marido, de heredar; estudiar... Esta cosmovisión era compartida, de modo general y en algunos aspectos más y otros menos, por los pueblos semitas de la región. La Arabia preislámica, por ejemplo,

"consideraba la sexualidad y especialmente a la mujer menstruante, como fuente de polución, de mancilla, como un polo de fuerzas negativas. La teoría sobre la 
mancilla manifestaba una visión de lo femenino que se expresaba por medio de un sistema de supersticiones y creencias que Mahoma quería condenar como consustancial a la esencia de la yahiliya (la época de la ignorancia) y de las creencias de la comunidad judía de Medina” (Mernissi, 2002 (1987): 91).

Lo "revolucionario" del Islam en la Arabia de los tiempos del profeta Mahoma, que compartía muchas creencias y prácticas judías, estaba justamente en esto: el profeta quería que su nueva religión cuestionara la religión judía, y así elaboró diferentes leyes en relación con la sexualidad: "el Profeta quería reaccionar contra el comportamiento fóbico de la población judía de Medina, que declaraba tabú a la mujer que tenía la regla: 'Les ordenó [a los creyentes del sexo masculino que le preguntaban sobre este tema] que comieran con sus mujeres, que compartieran el lecho, que hicieran con ellas lo que quisieran, salvo copular" (Iman an-Nissa'i, s.f: 152, citado por Mernissi, 2002: 91). Así, en el Islam predicado por el profeta Mahoma las relaciones sexuales y la menstruación rompían con la carga de "impuro" que prevalecía entre los judíos.

El éxito inicial de las mujeres en los primeros años del Islam consistía no solamente en haber recibido el apoyo legal y moral del profeta, o aleyas ${ }^{6}$ y suras exclusivas para ellas, como la Sura de las Mujeres (llamada de An-Nisâ), sino también en la posibilidad de abrir un espacio de reflexión sobre la situación desigual entre los sexos en la primera comunidad musulmana - espacio de reflexión que tiene su mérito por el hecho de que, al menos al nivel teórico, se planteó —e infelizmente se rechazó profundamente- e imaginar una sociedad de iguales.

Mahoma, entonces, tuvo que decidir, pese a sus utopías de una nueva sociedad arábiga más igualitaria, entre la igualdad entre los sexos y las clases sociales o el triunfo del Islam, sabiendo que este último implicaba permanecer en algunas prácticas tribales como la economía de la guerra y los botines, la esclavitud y la secundarización de la mujer, en boga durante la época preislámica. Como nos dice Fátima Mernissi, Mahoma era verdaderamente

"un profeta, un constructor de horizontes tan vastos que con sólo contemplarlos produce vértigo. Los animosos discípulos de los años 624, 625 y 626, trataban de aguantar, titubeaban, un paso adelante y otro atrás. Avanzaban como podían. Aquel asunto de las mujeres, por muy perturbador que fuera, tuvo un aspecto positivo: estrechó las filas de los hombres. Más que nunca, se dieron cuenta de que se necesitaban los unos a los otros para defenderse contra las agresiones, en su hogar como en el campo de batalla. Las discordias y enemistades se desvanecieron para dar paso a una complicidad revigorizante" (Mernissi, 2002 (1987): 162).

Después de la muerte de Mahoma en 632, Omar Ibn al-Jattab ${ }^{7}$ (que era yerno del profeta, padre de una de sus esposas llamada Hansa) se convirtió en el segundo califa ortodoxo. ${ }^{8}$ En esta época se solidificaron las desigualdades hacia las mujeres en el seno del Islam: dado su carácter, Omar se convirtió en el portavoz de la

"oposición masculina al proyecto igualitario del Profeta. Hombre de carisma excepcional, era partidario del mantenimiento del statu quo en el dominio familiar. Para él, como para numerosos discípulos a los que representaba, los cambios que el Islam tenía que introducir debían limitarse a la vida pública y a la espiritual. La vida privada debía seguir rigiéndose por las costumbres preislámicas, costumbres que Mahoma y su Dios rechazaban y condenaban por incoherentes con el nuevo sistema de valores musulmán, que insiste en la igualdad de todos, incluida la igualdad entre los sexos" (Idem: 164).

Esto significa que, con el pasar de los tiempos, los hombres de poder como Omar, quien por cierto re- 
presentaba a otros hombres, empezaron a utilizar lo sagrado en su beneficio para legitimar privilegios tanto en el ámbito privado como en el público. Y lo hicieron por medio de sus astucias jurídicas, lingüísticas y políticas, además de hacerlo en nombre de la tradición de los ancestros. Tanto que, incluso en vida del profeta, los opositores a su proyecto igualitario y de libertad eran muchos y persistentes: "al cabo de una generación, el hijo de un liberto no parecía digno del mando militar. Reivindicar la igualdad del esclavo ponía en juego, como en el caso de las mujeres, enormes intereses económicos" (Mernissi, 2002 (1987): 173).

Omar representaba los intereses y mentalidades de la mayoría de los hombres de Medina y de La Meca y además era un líder. Era más fácil que los seguidores del Islam se inclinaran hacia Omar en las cuestiones privadas y de relación entre los sexos, pues se trataba de privilegios de los hombres. El derecho a tomar la iniciativa sexual e imponer su posición, sea vaginal o anal y el derecho a gritar, regañar y a usar la violencia contra sus esposas eran prácticas de poder y control que los hombres de aquella época no estaban dispuestos a renunciar.

De este modo, en vez de basarse en aleyas como la 35 del Sura an-Nisâ (o sea, de las mujeres) que dice que "Dios ha preparado perdón y magnífica recompensa para los musulmanes y las musulmanas, los devotos y las devotas...", y con base en ella edificar una sociedad igualitaria con los sexos y las clases sociales, en lugar de dar riendas a las utopías proféticas, los califas tanto ortodoxos como los no ortodoxos han preferido basarse en otras aleyas como la 34 del Sura IV: "Los hombres tienen autoridad sobre las mujeres en virtud de la preferencia que Dios ha dado a unos sobre otros y de los bienes que gastan [en las mujeres]."

Los hombres se han apropiado del discurso religioso para legitimar sus privilegios, las mujeres se quedaron reducidas al espacio privado, que los musulmanes defendieron de los cambios propuestos por el profeta Mahoma y su Dios. Y así empieza la larga historia de sumisión y también resistencias de las mujeres de los Estados musulmanes, que se perpetúa, en algunos sentidos, a los pequeños grupos musulmanes en los países no musulmanes.

Actualmente, las feministas musulmanas como la marroquí Fátima Mernissi, la paquistaní Riffat Hassan, las egipcias Leila Ahmed y Aziza al-Hibri, la canadiense Shahrzad Mojab, la española Asma Lamrabet y Amina Wadud, han buscado, desde sus realidades específicas, hacer una exégesis y hermenéutica feministas del Corán y así sentar las bases de lo que podemos llamar feminismo musulmán, que tal como el feminismo occidental, busca desenmascarar el machismo, el patriarcado y hasta la misoginia presentes en la interpretación tradicional del Corán hecha por los hombres y buscan reconstruir nuevas interpretaciones que rescaten el importante papel de las mujeres en su cultura y religión.

En palabras de Sylvia Marcos, las feministas musulmanas buscan corregir las interpretaciones androcéntricas hechas del Corán, como lo afirma Riffat Hassan: 'Desde la constitución del Islam en $622 .$. , estas dos fuentes [el Corán y los haditts] han sido interpretadas siempre y exclusivamente por varones musulmanes que se han dado la tarea y arrogado el derecho de definir ontológica, teológica y sociológicamente a las mujeres musulmanas" (citada por Marcos, 2002: 53). Al buscar una interpretación del Corán menos sexista y más justa, que influya en la mejor calidad de vida y la defensa de los derechos de las mujeres musulmanas, estas feministas buscan contextualizar la historia del Corán para descubrir que algunas de las prácticas aceptadas y defendidas actualmente en el mundo islámico como la poligamia masculina, o la idea de que Dios creó primero al hombre, corresponden a un momento histórico que nada tiene que ver con la actualidad (Marcos, entrevista cimacnoticias, 2003).

Aunque algunos Estados islámicos y hombres musulmanes guardianes de la tradición hayan afirmado que el feminismo y la búsqueda de mejores relaciones de 
género no pueden conciliarse con el Islam, buena parte del esfuerzo de las feministas musulmanas busca probar lo contrario. Y lo hacen desde diferentes puntos de vista. Tal como no se puede hablar de un solo bloque monolítico del Islam, del mismo modo no se puede hablar de un solo feminismo musulmán. Al contrario, la multiplicidad del Islam genera una multiplicidad de feminismos musulmanes, siendo que las tres principales grandes corrientes son el feminismo islamista y el feminismo musulmán, por un lado; y el feminismo laico, opuesto al islamista, por otro lado. Los dos primeros están ligados a la tradición coránica, mientras que la última busca relativizar esta tradición y sostiene un discurso independiente de la religión.

En la comunidad musulmana sufi de San Cristóbal de Las Casas no se sigue el feminismo musulmán. Tal como explica una de las mujeres españolas de la comunidad sufi: "las madres, las mujeres musulmanas [somos las] que construimos el carácter de los niños y esa es una tremendísima responsabilidad y no estamos en contra del feminismo, ni tampoco a favor, lo que sí sabemos es que estamos contentas con nuestra función biológica" (Entrevista realizada por Morquecho, 2002, archivo personal del autor). ${ }^{?}$

\section{E1 Islam en San Cristóbal de Las Casas}

La comunidad Musulmana sufien San Cristóbal de Las Casas tiene sus inicios en el trabajo misionero de los andaluces Aureliano Pérez Yruela (Nafia), el Emir, y Esteban López Moreno, quienes junto con el mexicano Luis García Miquel llegaron a Chiapas a finales de 1994 y en 1995 fundaron la Unión Islámica de México, con sede nacional en el barrio Ojo de Agua, zona periférica de San Cristóbal de Las Casas (Lara 2002: 84).

A los nueve años de su fundación, la comunidad musulmana sufi de San Cristóbal de Las Casas cuenta con una membresía compuesta por españoles y mestizos, pero mayoritariamente por indígenas tzotziles y tzeltales, provenientes de Chamula, anteriormente expulsados $^{10}$, quienes migraron a la ciudad de San Cristóbal de Las Casas para iniciar una nueva vida. ${ }^{11}$

Este hecho ha influido en la propia dinámica de la ciudad, la cual ha presentado en las últimas décadas un significativo crecimiento demográfico en virtud de las migraciones mayoritariamenteindígenas. Migraciones que igual que lo que ocurre en México y el resto de Latinoamérica salieron del campo hacia la ciudad en búsqueda de mejores condiciones de vida, traducidas en mayores oportunidades de trabajo, salud y educación.. Además, una causa importante para las migraciones indígenas hacia San Cristóbal de Las Casas son las expulsiones por motivos económicos, políticos y religiosos que han interferido directamente en la organización social, política y económica de los parajes. ${ }^{12}$

Pienso que esta historia debe ser tomada en cuenta cuando nos aproximamos al fenómeno religioso y de inmigración de las familias indígenas chamulas a la ciudad de San Cristóbal de Las Casas y tomamos en serio lo que dice el antropólogo Gaspar Morquecho sobre los indígenas chamulas, quienes "han forjado en su historia peculiaridades que los hacen diferentes a los demás tzotziles de Los Altos de Chiapas" (archivo personal de Morquecho, 2004). Como ejemplo, cito el significativo hecho de que

"dos de las familias chamulas que han jugado un papel importante en la historia reciente de San Juan y hoy son musulmanes: una de ellas es la familia Checheb, uno de los clanes que enfrentó al cacicazgo chamula a principios de la década de 1970 y, la otra, son los hijos, las hijas y las/os nietas/os de Miguel Caxlán, un dirigente y predicador presbiteriano que fue brutalmente asesinado por órdenes de los caciques de San Juan" (Idem).

En 1999 hubo un conflicto interno al interior de la comunidad musulmana sufi asentada en San Cristóbal. Éste tuvo como consecuencia la salida de algunos indí- 
genas quienes adoptaron la corriente teológica sunníy se afiliaron al Centro Islámico de México con sede en el Distrito Federal.

Los musulmanes españoles que fundaron y dirigen la Misión para el Da'wa en México (nombre de la comunidad) son de orientación sufi-murabitum. El sufismo, como el sunnismo y el chísmo, es una de las tres grandes subdivisiones que se destacan en el interior del Islam. La corriente sunni es considerada la más antigua y ortodoxa, que surgió paralelamente a la corriente chiíta, ambas en el siglo $\mathrm{VII}^{13}$. El sufismo originalmente se deriva del chiísmo, y es considerada como una rama mística y pacifista de interpretación y vivencia del Islam, también minoritaria en comparación con la sunnita. Su influencia se destaca en regiones de la India, Turquía, Marruecos e Indonesia (Alexander, 2002: 9).

El Movimiento Mundial Murabitum, a su vez, es un movimiento nacionalista cuyo fundador y guía espiritual es el sheik Abdul Qaeder as Sufi al-Morabit, un escocés convertido al Islam alrededor de los años sesenta. Este Movimiento tiene como misión reconstruir y difundir las primeras comunidades musulmanas fundadas por Mahoma en Medina durante los primeros años de la hégira. ${ }^{14}$ Estas comunidades son vistas por los partidarios del Movimiento Mundial Murabitum como los modelos perfectos de vivencia del Islam en los aspectos personales, cotidianos, organizativos, políticos y económicos (Entrevista 2 con Fátima: 3 de abril 2004). Buscan, así, crear comunidades autónomas al Estado, autosuficientes, cuya economía está organizada en gremios $^{15}$ y manejan una moneda común de oro o plata. Rechazan el capitalismo, el papel moneda y los bancos por causa de la usura explícita en ellos.

Los musulmanes sufis-murabitum trajeron el Islam a San Cristóbal de Las Casas a finales de 1995. Buscaron primero un contacto y la conversión de los miembros del Ejército Zapatista de Liberación Nacional, y a la recusa de éstos, intentaron ganar la confianza de las comunidades indígenas por medio de la Organización no-
Gubernamental Desarrollo Económico Social de los Mexicanos Indígenas, A. C (DESMI), con un proyecto político y económico en contra del capitalismo y sus instituciones.

Respecto al hecho de que los y las indígenas de San Cristóbal aceptaron el Islam y pasaron a formar parte de la comunidad musulmana sufi, identifico tres motivos principales: El primer motivo de aceptación del Islam por parte de las y los indígenas de San Cristóbal, fue el acercamiento de los musulmanes españoles a Domingo López Ángel. Domingo López Ángel es una personalidad conocida, respetada e influyente entre los indígenas de San Cristóbal de Las Casas. Fue líder de los expulsados de San Juan Chamula, él mismo fue expulsado. Fue líder político, diputado por el PRD y pastor evangélico de mucha influencia.

La asimilación de estas familias chamulas al Islam ocurrió a partir del momento en que Domingo López Ángel conoció a los musulmanes y se convirtió al Islam juntamente con sus seguidores. La mayoría de las mujeres indígenas chamulas musulmanas son descendientes de las familias que fueron expulsadas del municipio y parajes de San Juan Chamula en diferentes ocasiones a partir de 1974 y pasaron a formar las colonias populares que rodean San Cristóbal de Las Casas, por ejemplo, las colonias La Hormiga, Palestina y La Esperanza. Domingo López fue, desde los inicios, uno de los principales líderes políticos y espirituales de estas familias de expulsados.

El segundo motivo de aceptación del Islam por parte de las y los indígenas se refiere al discurso social, político y económico del Emir, Aureliano Pérez Yruela. Este discurso sigue los planteamientos murabitunes de crear una sociedad poscapitalista que, según ellos, sólo puede surgir a partir de la propuesta del Islam. Proponen antes de todo, una sociedad sin usura y por lo tanto sin bancos ni papel moneda, y abogan por el uso del dinar (moneda de plata) y el dirjamy (moneda de oro). En resumen, este discurso del Emir puede haber favorecido y de cierta forma influido a que las y los indígenas que 
viven en San Cristóbal entraran en la comunidad musulmana, y pasaran a creer que el Islam es la última revelación de Dios.

En un documento que Aureliano Pérez Yruela entregó al DESMr en 1995, con el título: “Chiapas: demasiado pequeña para liberarse a si misma, pero suficientemente grande para liberar al mundo: Un plan para liberar a Chiapas de la tirania del sistema bancario y con él de todas las consecuencias de miseria y humillacion, que durante siglos han empobrecido y bumillado a las gentes de esta tierra. Un modelo para hacer de Chiapas una luz de referencia para todos lospueblos del mundo" se contiene la propuesta económica que los musulmanes españoles sufi-murabitunes de San Cristóbal de Las Casas proponen para Chiapas y que puede ser uno, pero no el único, de los elementos principales del discurso social del Emir quien favoreció el hecho de que los indígenas entraran en la comunidad musulmana, y creer que el Islam es la última revelación de Dios. En dicho documento hay informaciones riquísimas sobre los intereses, utopías y objetivos de los musulmanes en San Cristóbal, ${ }^{16}$ en cierta forma coincidentes con los intereses de los indígenas en ser parte de otro proyecto o sistema económico, que los incluya de una forma más considerada que el capitalista.

El tercer motivo, en mi opinión, se refiere a la importancia que los y las indígenas conceden a la religión, a lo sagrado en sus vidas. Es sabido que la mayoría de los indígenas de San Cristóbal de Las Casas han cambiado más de una vez de religión. Estos cambios religiosos o, en palabras de Carolina Rivera, este "nomadismo religioso" hace parte, como es de suponer, de las estrategias que estos indígenas urbanos de San Cristóbal han adoptado para su supervivencia. Lo interesante está en que los indígenas han buscado la relación con lo sagrado en estas estrategias, no se han quedado solamente en la organización social o política, señal de cuánto les importa lo sagrado, aunque no tanto lo denominacional. Considero que estas relaciones con lo sagrado hacen parte de sus reelaboraciones identitarias, razón por la que permanecen.
Además de los motivos que cité, puede haber otros que todavía no identifico. No obstante, me es importante aclarar que no establezco una jerarquía entre ellos. Es decir, los motivos que llevan a un cambio religioso son tanto externos a la persona, por ejemplo, los dos primeros que cité, como internos, por ejemplo, las cuestiones existenciales y espirituales de cada persona. Y además, pueden ocurrir motivos simultáneos, o circunstancias particulares que favorecen el cambio.

Hablo de cambio y no de conversión religiosa porque entiendo la conversión como un proceso personal que se inicia con el cambio. O sea, primero hay un acercamiento y conocimiento de la religión, en este caso al Islam. Las personas necesitan, en un primer momento, haber oído y hablado de la religión, de sus miembros, los ritos y formas de creer. La conversión es un proceso constante, casi siempre inacabado, de modo que la persona continuamente va elaborando y reelaborando su pertenencia y lugar en el grupo, las formas en que vive y experimenta la relación con lo sagrado.

Antes de terminar, me gustaría destacar la importancia de la religión en las reelaboraciones identitarias. Para hablar de cultura, religión e identidad es necesario entrar en el mundo de las subjetividades humanas, de un proceso que ha marcado el desarrollo humano como especie, del cual hace parte la cultura. En este sentido, Heinz Dieterich explica que la identidad puede ser entendida como el principio organizador de las estrategias que el ser humano desarrolla para su supervivencia (2001: 130). Del mismo modo, la religión ha ejercido, a lo largo de la historia y en casi todas las organizaciones sociales y culturales, un papel fundamental para ubicar a los seres humanos en el mundo, garantizar su supervivencia y desarrollar su cultura, su identidad, y ayudarles a comprenderse a sí mismos y lo que estaba a su alrededor. ${ }^{17}$

Si concordamos con Dieterich en su afirmación de que desde sus orígenes la existencia del ser humano ha estado marcada por la reflexión sobre sí mismo y su lugar en el universo, que se manifestaba por medio de 
las preguntas sobre el sentido de la existencia, tales como “¿de dónde vengo?, ¿quién soy?, ¿cuál es el sentido de mi ser?, ¿cuáles son las fuerzas del cosmos y cómo pueden influenciarse?, ¿hay una vida después de la muerte?” (Dieterich 2001: 132), podemos afirmar que hay una intrínseca relación entre cultura, religión e identidad, y que ambas instancias han ejercido un papel fundamental en la formación de la identidad humana. La religión, a través de la cultura, ha sido una de las primeras instancias que ha buscado, por medio de la respuesta a estas preguntas, dar significado a la existencia humana y en muchos casos las continúa dando a un gran número de personas.

La capacidad de crear significados es intrínseca a los seres humanos, quienes al enfrentarse con el mundo lo significan a partir de los interrogantes ontológicos citados arriba, cuya función consiste, antes de la satisfacción de inquietudes metafísicas, en favorecer el control de la realidad natural y social" (Idem. 133). El dar significado posibilita la comprensión del mundo, que es una forma de conocerlo, controlarlo, dominarlo y transformarlo, de modo que la existencia humana pueda desarrollarse y persistir en el tiempo y en el espacio. De este modo surgen las culturas y las sociedades, y dentro de ellas las instituciones encargadas de transmitir estos conocimientos, como es el caso de la religión.

Parto, entonces, del hecho de que la religión se encuentra en las matrices culturales y que así ha posibilitado que los seres humanos, sean o no creyentes, ${ }^{18}$ añadan elementos en sus identidades individuales y colectivas que les permitan comprenderse, distinguirse e identificarse en el mundo en que viven. Pensar en la religión y considerarla como un factor importante en la formación de las culturas e identidades humanas se vuelve indispensable si queremos comprender de modo más completo nuestras culturas y sociedades. Por "más completo" me refiero a las posibilidades de comprender y aproximarnos a la cultura tanto de modo subjetivo como objetivo por el simple hecho de que el ser humano comporta ambas dimensiones en su ser, y cuya mayor parte de las acciones y sentimientos se ubican en sus subjetividades.

Tomando en cuenta el hecho de que la identidad individual tiene un carácter intersubjetivo que emerge en la relación con otras identidades en el proceso de interacción social (Giménez 2000: 50), las identidades de género y etnia se configuran como extensiones de la identidad social. La identidad étnica, conforme expresa Gilberto Giménez (2000: 58) remite "siempre, a contextos históricos y socialmente específicos, y se puede esperar razonablemente que variarán en cuanto a su composición y significado según los diferentes procesos de etnicización que les dieron origen”. El mismo autor sigue a Fredrik Barth, quien afirma que "la etnicidad, que es un producto del proceso de identificación, puede definirse como la organización social de la diferencia cultural" (Barth, 1976:15, citado por Giménez, 2000: 59).

Esto significa, en relación con las poblaciones indígenas, que la identidad étnica conjuga algunos componentes culturales básicos como un pasado, una tradición histórica o memoria colectiva, un territorio; un lenguaje por medio del cual se elabora y expresa los símbolos y visiones de mundo particulares de cada pueblo; un sistema de parentesco muy importante para el sentimiento social de pertenencia grupal y por fin un "complejo religioso-ritual que actualiza, reafirma y renueva la identidad del grupo, mediante la dramatización de su visión de mundo, la vida y la muerte" (Giménez, 2000: 59-60).

La identidad de género se refiere a los roles socialmente construidos y asignados a los seres humanos en función de su sexo, es decir, los modelos tradicionales de ser mujer u hombre en cada cultura y de acuerdo con el momento histórico particular. De modo general, en la cultura occidental el modelo tradicional de hombre comporta características de fuerza, poder y razón - como pilares tradicionales masculinos_-, mientras que la mujer comporta características de debilidad, pasividad 
y emoción — como pilares tradicionales femeninos-. Estos conceptos (de masculinidad y feminidad), vale aclarar, son productos históricos, que varían de una época a otra y de una cultura a otra. Del mismo modo, nunca fueron estáticos y tampoco se aplicaron a todos los hombres y todas las mujeres a la vez. Al contrario, se fueron reelaborando en el transcurrir del proceso histórico y estuvieron marcados por la inconstancia, pasando por reacomodos y cambios significativos en el transcurso de la historia. ${ }^{19}$

Ambas identidades de género y etnia se conjugan en las mujeres indígenas. Las identidades son, en fin, construcciones socio culturales, surgidas de la necesidad constante de crear sentido a la existencia y por lo tanto están marcadas por la interacción humana entre los demás y con su entorno. De ahí se desprende el hecho de que el ser humano desarrolle múltiples identidades históricas individuales y colectivas, que le permiten distinguirse y ubicarse en el mundo en que vive.

\section{Las indígenas chamulas musulmanas sufis de San Cristóbal de Las Casas}

De acuerdo con una entrevista realizada con una Salija, una española que es esposa de uno de los dirigentes de la comunidad musulmana, hay en ésta alrededor de 35 o 40 mujeres indígenas la mayoría descendientes de las familias expulsadas del municipio de San Juan Chamula. Cuando le pregunté sobre la forma en que se aproximaron a las indígenas, Salija me contestó:

\footnotetext{
"Se estuvo hablando... Explicamos el din ("forma de vida musulmana"), cómo hacer la oración, los asuntos del Islam...Hay cosas que se aprenden rápidas, otras son despacio: es un proceso. Estas cosas se enseñaron basándonos en el ejemplo del profeta, se les enseñó el adab ("cortesía", educación hacia los demás, las personas, los animales, todo). Hubo una relación con ellas. Nosotros [ella y el Imán] llegamos después del
}

Emir, unos siete u ocho meses. El Emir ya conocía a algunos en el mercado, se conectó en el Barzón, algo así. Una cosa que es muy importante es que los únicos aquí que han dado una respuesta, shahada ${ }^{20}$, fueron los indígenas. Cuando llegué sólo había una mujer indígena, Zainab, una mujer muy, pero muy generosa: venía a la casa, siempre traía algo de comer para compartir, comíamos juntos... Es una de las mujeres más transparentes de la comunidad. También invitábamos a los indígenas a las fiestas, la fiesta del Cordero, la del Ramadán... Las indígenas que ya estaban en la comunidad traían alguna amiga para platicar" (Salija, entrevista 05, 02 de febrero 2004).

Además de esta forma aparentemente tímida y discreta de aproximación, Salija comentó:

"Un dato curioso para mí es que se hacen grupos familiares grandes, cuando uno se convierte todo el clan familiar viene, como por ejemplo Ibrahim [su yerno], que cuando se enteró que había musulmanes aquí vino a preguntar, hizo su shahada [confesión de fe, atestiguar que sólo hay un Dios, Alá] y trajo a su papá, su tío y sus familias. Cuando yo me convertí, eso no pasó, mis papás no se convirtieron al Islam. En España no vi eso, eso sólo pasa aquí” (Idem).

Vale la pena recordar que Salija no habló de la presión por parte de los y las españolas fundadoras y dirigentes hacia algunos o algunas conversas de que traigan a sus familiares a la comunidad. Este hecho me fue revelado por Fátima, una de las mestizas que durante un tiempo fue parte de la comunidad musulmana y vivió esta presión.

Cuando le pregunté por qué las indígenas han buscado al Islam, Salija me contestó que su cambio hacia el Islam no fue necesariamente resultado de la predicación y misión de los y las españolas musulmanas. Entre otras cosas dijo: 
"Es que tú no buscas al Islam, tú te sometes a Alá (...) Alá llegó a los indígenas. Hay muchos casos en que las mujeres indígenas son musulmanas y sus maridos no. (...). Esto que apenas la mujer se convierta no es aceptado en el Islam, pues la mujer musulmana tiene que estar con un hombre musulmán. Dadas las condiciones, por estar casado desde antes, no hemos dicho nada. Se espera que el hombre también cambie para musulmán, pues a largo plazo puede dar problemas. Está permitido en el Islam al hombre tener más mujeres, pero no entre hermanas de sangre o entre madre e hija. Hay un caso en que desde antes un hombre estaba casado con dos hermanas, no dijimos nada porque estaba casado antes. Pero no es permitido" (Idem).

Los motivos que han llevado a las mujeres chamulas a ser parte de la comunidad musulmana sufien San Cristóbal de Las Casas varían mucho de mujer a mujer. Algunas se han convertido motivadas por sus maridos, como Sharifa, Mariam, Carima, y Aísha, todas ellas provenientes de Chamula, entre 28 y 34 años de edad, y que viven en San Cristóbal desde que son niñas. Las tres han sido víctimas de las expulsiones en el municipio de San Juan Chamula en la década de los setenta. Otras mujereschamulas entraron en la comunidad desde que eran niñas, por motivos de la conversión de sus papás o algún otro familiar, como son los casos de otra Carima, Firdaus, Janna, Jaiar, Safia y Salima. Sin embargo, estas mujeres me han dicho que ahora están en la comunidad porque les gusta, por la forma en que se puede vivir compartiendo la comida, haciendo trabajos en conjunto, aprendiendo otros oficios, trabajando de maestras en la escuela.

Una cosa muy importante es que ellas acreditan que el Islam es la última revelación, el último mensaje de Dios para la salvación de los seres humanos, lo que las llevó a cambiar el nombre, a aprender y seguir los rituales de oración y purificación y cumplir los pilares del
Islam; algunas cambiaron la forma de vestirse y, por la convivencia con las españolas musulmanas, las más jóvenes cambiaron la forma de hablar, y prácticamente todas cambiaron los hábitos alimentarios.

Otro motivo que la mayoría de las entrevistadas me dió para explicar el porqué les gusta ser parte de la comunidad sufies por el hecho de que tienen un espacio para ellas mismas, trabajar y vivir en comunidad, pues se sienten protegidas y están más unidas. La comunidad musulmana es un espacio donde se comparte la vida en sus más mínimos detalles, como la comida en conjunto, los hijos en la escuela, las casas, los horarios de la Yumma ${ }^{21}$, del Dikra ${ }^{22}$ y el salat, que son los principales rituales de la comunidad, además de las fiestas y el ayuno durante el mes del Ramadán. También hacen paseos en conjunto, salen a tomar café, y, como me han dicho: "no es cada quien en su casa. No. Hay una vida en común". Las mujeres más jóvenes saben leer y traducir el árabe transliterado, y ayudan a las más grandes en esta tarea.

Todas las entrevistadas manifestaron una gran espiritualidad y así demostraron el lugar privilegiado que dan a la religiosidad en sus vidas. Sharifa por ejemplo dijo que: "Sí, porque la oración haces cinco veces al día. Es obligatorio. Si te haces falta una, pues tienes que vas hacerlo. ¿Por qué? Porque es tu obligación de hacerlo. Pero y además también si no haces un día la oración, como que no te quedas tranquila, si ya has hecho de todo, te quedas tranquila, te quedas tranquila, te vas a la cama a dormir tranquilamente. Pero si te falta una, como que alguien te dice que te falta algo. Por eso tengo que hacer la oración" (Entrevista a Sharifa, 17 de febrero del 2004). Y Janna, al igual que su hermana Sharifa, tampoco puede dormir sin haber hecho su salat:

"Sí, me gusta el salat, no me... no puedo dormir así si no hago el salat, tengo que haber cumplido y todo, porque así [está] escrito el Corán que hay que hacer cinco veces por día. Lo hago cinco veces por día, 
primero a las 6 de la mañana, después la una y media de la tarde, a las 8 de la noche. También desayunar y todo ahí está escrito. ¿Para ti cuál es la diferencia entre el Corán y la Biblia? Bueno, la diferencia es que la Biblia no dice nada así de la oración 5 veces, ni ayunar, sí ayunan pero tres días y sin comer nada en la noche así. En cambio el Corán.... ayuna también, levanta a tomar el desayuno a las 5, hay gente que desayuna a las 6..." (Entrevista con Janna, 16 de febrero del 2004).

Este hecho explica el por qué se han esforzado para aprender los pasos de los rituales de purificación y para hacer el $\operatorname{salat}^{23}$ o el ayuno en el Ramadán. Todas ellas dijeron que al principio les costó; sin embargo, los dirigentes españoles, así como las mujeres españolas, les han explicado muy bien y con paciencia. Algunas ya han ido a La Meca a cumplir con el Jajj ${ }^{24}$ y se han sentido muy contentas en "visitar la casa de Alá".

Todas las entrevistadas ven el Islam como la verdadera religión que les proporcionará la salvación y el jardín durante el Último Día. La joven Carima, por ejemplo, me dijo que el Islam, para ella:

“...es la verdad. Estoy tranquila. Sí... es bueno... porque crees en un solo Dios, que es la verdad, tu vas a tener una vida segura después de la muerte... Si... porque después de la muerte está la vida verdadera que vas a vivir después de esa (...) En todo hay diferencia entre el Corán y la Biblia, todo, la Biblia pues dice tanta cosa que... que no... que no tiene que ver con nosotros... El Corán yo creo que... las cosas que dice, por ejemplo, adorar un solo Dios y a su profeta, su mensajero, es lo correcto. (...). Si... Yo creo en las bendiciones que Alá me da. En mi casa no había... yo creo que mi madre no ganaba, no comíamos bien... (...). Estoy tranquila pues, y saber que voy a tener una vida segura más adelante después de que me muera, que si creemos en Alá y en su mensajero vamos a tener una vida eterna" (Entrevista a Carima, 18 de febrero del 2004).
Por esto, las entrevistadas que están casadas y también las solteras no manifestaron ninguna inconformidad con el hecho de que sus maridos puedan tener otras esposas. Todas las entrevistadas dijeron que si esto está determinado de antemano por Alá, que así sea. Vale recordar que en la tradición indígena chamula, esto es algo común, aunque se da en condiciones diferentes y tiene otro sentido, como por ejemplo, no es una práctica reglamentada ni controlada, sino que en muchos casos consiste en casos de permisividad e infidelidad masculinas. Ahora que son musulmanas, las mujeres chamulas me han dicho que aceptan que sus maridos tengan otra mujer si la pueden mantener y dar el mismo trato a las dos. Tres de las entrevistadas, sin embargo, han reconocido que al principio, esta posibilidad les ha disgustado o preocupado, pero si este es el destino trazado por Alá, tienen que aceptarlo a cambio de recibir el jardín como recompensa de vida eterna. Sharifa me explicó la importancia del Islam en su vida cuando le cuestioné si no se quedaría celosa con el hecho de estar permitido que su marido tenga hasta cuatro esposas:

- ¿No te pondrías celosa?

_-Nooo... Si quiero que mi vida [sea] más feliz, ¿¡cómo que no voy a aceptarlo!? Sólo pero si soy una mujer si no quiero aceptar y si me voy ir al infierno pá que se sepa. Mejor que lo acepto mi compañero, como que tengo derecho al jardín (...). Pues el jardín donde se usa la vida en el juicio final: a donde se va sin sufrimiento, para donde se va después de todo. Por eso hay mucha religión que hay infierno, que hay un jardín. Por eso si alguna mujer que quiere tu marido que puede morirse muy joven, pero si quieres el jardín tiene que aceptarlo. Pero si haces un decreto nuestro marido igual que va a tenerlo, pues si hace un decreto y todo hace sentido, él va a tenerlo, pues ya está decretado, lo decreta Alá, está decretado por Alá. Por eso hay algunos que ya tienen dos... Y yo sílos acepto los decreto (...). Sí, porque 'toy haciendo por Alá (...). Por eso te digo que hay infierno pues y hay jardín 
pues. Estoy luchando por el jardín, no me voy a querer ir al infierno, a nadie quiere ir al infierno" (Entrevista a Sharifa, 17 de febrero del 2004).

Sobre el uso del velo, las mujeres chamulas más jóvenes han revelado que, al principio, les daba pena usarlo. Las personas les molestaban en las calles, les decían que tenían piojos, o que no tenían pelo, además que era muy complicado ponérselo y usarlo correctamente. Ahora ya les gusta, no sienten diferencia, al contrario, se "siente que es bonito". Janna dijo que le gusta usar el velo: "Sí, yo sí. En la casa puede quitar sólo es importante llevar el velo en la calle para que te proteja, pues para que no te molesten. Ahorita no, ya no me da pena, antes sí me daba pena, porque no estoy acostumbrada a llevar el velo, ahorita ya no" (Entrevista con Janna, 16 de febrero del 2004). Salima, la hermana de Carima, me dijo que: "Sí, me gusta, pero antes no me gustaba, ahora ya. Me daba pena, también este... te decían que tienes piojo, que no tienes pelo, no sé, no me gustaba, ahora sí me gusta" (Entrevista con Salima, 16 de febrero del 2004). Y Firdauss, me dijo que: "Es como una protección para nosotras, una protección contra todos los males. Es más cubierto, no enseñas nada" (entrevista con Firdauss, 16 de febrero del 2004).

Las mujeres chamulas más jóvenes me han dicho que, por el hecho de que tanto su padre como su madre son musulmanes, ya no se pelean tanto, razón por la cual ha cambiado la dinámica familiar. Tres de las entrevistadas han dicho que la situación financiera de la familia está mejor ahora que son musulmanes, y que los hombres musulmanes son diferentes, ayudan más a la mujer. Una me dijo que está más segura y contenta que sus hijos estén en la escuela, la madrassa, y una me dijo que se siente más bonita, más inteligente:

"Alá ya me ha ayudado bastante. Primero me ayudó a venir hasta acá donde estoy, en católico no, porque no me siento muy bien allá, no vivo bien el católico, no sé... soy un poco así, Janna. Ahorita me ayudó y ayudó para que a salir adelante, así sola, con mi vida (...). Alá me ayuda, tengo dinero, compro mi ropa y todo, soy muy contenta, estoy feliz. Mi vida es mejor ya, es que [cuando era católica] tengo problemas con familiares 'toy muy tristes, falta mucha cosa en la vida. Ahora ya estoy muy tranquila" (Entrevista con Janna, 16 de febrero del 2004).

Todas ellas han dicho que su vida ha cambiado mucho desde que son musulmanas, y que están más felices, más limpias, más unidas y más tranquilas.

\section{Los cambios étnicos y genéricos}

El impacto social que ha provocado en las mujeres chamulas ser parte de la comunidad musulmana es notorio y hace parte de los cambios que vienen ocurriendo al estar en el espacio urbano, algunas hace más de treinta años. Antes de ser musulmanas, en su mayoría las indígenas chamulas eran evangélicas y tenían algún tipo de trabajo remunerado en San Cristóbal de Las Casas, y de esa manera participaban activamente de la economía familiar, además de tener una doble jornada de trabajo, responsabilizándose del cuidado de la casa y la crianza de los hijos e hijas.

La comunidad musulmana ha proporcionado a las mujeres indígenas un espacio de solidaridad y comunión. Algunas ahí viven, trabajan y oran, compartiendo casi todo. Las casas en el espacio de la comunidad están lado a lado o frente a frente una de la otra. Es un espacio de protección, que no necesariamente las priva de la libertad. La mayoría de las indígenas trabajan en las labores de la comunidad: en la panadería, en la pizzería La Alpujarra que la comunidad tiene en el centro de la ciudad, en los talleres de pintura de seda o de costura, y para ello algunas reciben una gratificación. Se trata de una gratificación, y no salario remunerado, pues los sufismurabitum se oponen al trabajo asalariado. Sin embargo, las mujeres chamulas que he entrevistado, están muy 
contentas con esta gratificación, pues la comunidad además les provee casa, la escuela para sus hijos e hijas y, conforme me han dicho Carima, Sharifa y Safia, les proporciona también una forma de comer mejor que cuando no eran musulmanas. Las mujeres más grandes, ya ancianas, tienen un lugar destacado en la comunidad, además de ser muy respetadas: son las que son servidas primero, muchas veces por las españolas más jóvenes.

Algunas me han dicho que su vida ha cambiado mucho a partir de los nuevos hábitos de higiene, de bañarse todos los días y sentirse más limpias. Todas las entrevistadas me dijeron que el hecho de hacer el salat, les ha cambiado la vida.

Confieso que entender y explicar este cambio es para mí un poco difícil por tratarse de algo muy subjetivo, como me dijo una de ellas en alguna ocasión: "estás tú y Dios frente a frente". Me gustaría detenerme un poco en esta cuestión.

La espiritualidad que ellas viven por medio de los rituales del Islam yo la comprendo desde las herramientas que me aporta la teología, como una forma de tener a Dios como aliado, protector y defensor, no solamente en esta vida, sino también en la vida después de la muerte, en la cual ellas creen. Dios es una puerta que se abre para ellas tanto de manera individual como en grupo de mujeres creyentes, mujeres que comparten una historia similar. La comunidad musulmana se convierte, en este aspecto espiritual y subjetivo, como una de las puertas del capital simbólico por la cual ellas pueden entrar y salir, de acuerdo con sus necesidades.

Y con Dios ellas pueden dialogar, contarle sus dificultades y sus necesidades, además de sus sueños y esperanzas. Y ellas creen que Dios sí las oye, tal como son. Las oye, las ve, las considera, las ayuda y les dará la recompensa merecida por esta vida de sacrificio y privaciones: un paraíso en el cual descansar en paz, sin agresiones, sin violencia, ni insultos, ni humillaciones. La religión, en este caso el Islam, llega como la verdadera y última revelación divina para la salvación de las perso- nas. Y así, ellas encuentran nuevamente una forma de nombrar sus males, encuentran otras y nuevas formas de dar sentido a su identidad como mujeres de fe, encuentran nuevas palabras para expresar sus necesidades y sus dolores.

La pregunta que surge aquí es: si ellas ya tenían un Dios en quien confiar desde que eran evangélicas, ¿por qué es mejor o más cercano el Dios musulmán? Esto lo respondo con sus propias explicaciones. Sharifa, por ejemplo me dijo, entre otras cosas, que ". . la diferencia con los musulmanes es que te enseñan de todo, del trabajo, de todo eso (...), me enseñaron todo, hacer las oraciones, la limpieza, el ayuno, y todo (...). Así yo vi que era diferente y estoy feliz que hay musulmanes (...). Es más bueno todo, te enseñan de todo, al cambio las otras religiones no te enseñan, al contrario (...) Gracias a Alá que vinieron los musulmanes...”. Janna, por su vez me dijo que la diferencia está en que “... es diferente como la limpieza y todo. En el Islam tiene que estar limpio, a mi me gusta estar limpio. Los católicos y todo no se limpia, no hace la limpieza, se bañan todo, pero los musulmanes se limpian, se lavan cuando tiene que orar (...). Me gusta mucho el salat, no me puedo dormir si no hago el salat, tengo que haber cumplido y todo, porque así [está] escrito en el Corán”.

Firdaus, que igual que Janna ya se fue a La Meca, me dijo que la diferencia está "en la manera de ser de la gente: son más amables y simpáticos (...). También hay diferencia en la manera de orar, la oración, casi todo. Los musulmanes todos los días hacen los horarios, ir a la mezquita diario. Los evangélicos cada sábado". Carima me dijo que cree que el Islam "es la verdadera religión, porque es muy distinto de las otras religiones. Por ejemplo, los católicos creen en los santos, todo, pero nosotros no, creemos en Alá, que es el único Dios que hay en el mundo y en nuestro profeta que es Mohammed". Cuando pedí que Salima me diera dos ejemplos de la diferencia entre ser musulmana o evangélica, ella me dijo que: "te sientes bien aquí con 
los musulmanes, sientes que es lo mejor. Todo me gusta y Alá me ha ayudado mucho".

Estas respuestas me ayudan a comprender que no se trata solamente de Dios y sus preceptos, sino de la forma en que una se siente o no se siente parte de la comunidad. Curiosamente las mujeres indígenas chamulas musulmanas sufis se sienten mejor en una comunidad liderada por españoles que por una liderada por indígenas como ellas. Hay algo en estos españoles que las convence, y una de estas cosas, además del discurso social, económico y político del Emir, es la forma en que se llega a vivir comunitariamente, que es algo muy valorado por las y los indígenas. Más de una de las entrevistadas ha dicho que la forma en que se vive en la comunidad, en que son tratadas y las posibilidades que hay en ella de mejorar de vida es uno de los motivos que las hace sentirse bien. Y por ser mujeres profundamente religiosas, el poder unir este bienestar con la creencia en que el Islam es la continuación del mensaje de Dios, y que es la última revelación, las hace sentirse en el camino correcto de la fe, o, como dice una de las españolas, en la evolución natural de la fe, que es pasar de una religión de la naturaleza hacia el cristianismo y ahora hacia el Islam (entrevista con Salija, 17 de febrero 2004).

\section{Conclusiones}

He citado como cambios notorios en la identidad étnica de las indígenas provenientes de Chamula, ahora musulmanas sufis, el cambio de vestimenta, de lenguaje, de régimen de alimentación, de convivencia y en las formas de lidiar con el propio cuerpo como los principales cambios derivados de la pertenencia a la religión musulmana. Es sabido que tradicionalmente la identidad indígena está asociada al espacio de la cultura y el territorio de la comunidad. Sin embargo, ahora podemos hablar también de una cultura indígena de las ciudades y de las prácticas y costumbres que se han cambiado o adaptado como una forma de renovar la identidad.
En lo que se refiere a los cambios en la identidad de género de las chamulas musulmanas, éstos son muy sutiles y, en verdad, más que cambios representan una continuidad creativa en las formas de ser mujer e indígena en la ciudad, participantes no solamente de una religión, sino también de una organización como mujeres, en este caso en la comunidad musulmana.

El aspecto de la poligamia masculina y de la visión del cuerpo de las mujeres como objeto de deseo masculino y que por eso debe ser cubierto con el velo y faldas largas es algo que, en mi opinión, permanece como ejemplo de la continuidad de la cosificación de la mujer. No se trata, en la opinión de algunas feministas musulmanas y yo comparto ese punto de vista, de que las mujeres cubran o escondan el cuerpo, sino de que tengan la libertad y el derecho de no ser molestadas morbosamente por los varones en ninguna circunstancia. Si el respeto hacia la mujer y su cuerpo tiene como condición el que éste no se enseñe, entonces, no creo que se haya avanzado todavía en la libertad femenina de transitar en el espacio público como un espacio que también le pertenece. La poligamia masculina es un asunto muy controvertido en la comunidad musulmana sufide San Cristóbal. No son muchos los casos de poligamia en la comunidad. Es sabido, además, que esta práctica es común entre los indígenas chamulas, aunque se da de manera diferente, como ya lo comenté arriba. Sin embargo, la idea de que los hombres puedan tener más de una mujer, y que éstas se apoyen mutuamente en la crianza de los hijos y las tareas domésticas, no deja de ser una señal de que el espacio privado y reproductivo es visto como exclusivo de las mujeres.

Concluyo de manera general que los aspectos étnicos y genéricos vividos por las mujeres provenientes de chamula, ahora asentadas en San Cristóbal y convertidas al Islam, están en proceso de transformación y adaptación, si se toma en cuenta que la identidad individual, en este caso en sus aspectos de género y etnia, es un proceso abierto, no estático, que se recrea continuamente. 


\section{Notas}

1 "Una religión es un sistema de símbolos que obra para establecer vigorosos, penetrantes y duraderos estados anímicos en los hombres [sic] formulando concepciones de un orden general de existencia y revistiendo estas concepciones con una aureola de efectividad tal que los estados anímicos y motivaciones parezcan de un realismo único" (Geertz, 1995: 89).

${ }^{2}$ Las y los chamulas son los indígenas originarios del municipio de San Juan Chamula, ubicado en la región de los Altos de Chiapas. Estos indígenas existen desde antes de la época de la conquista española del territorio chiapaneco, ocurrida a partir de los años de 1523 por Luis Marín.

${ }^{3}$ San Cristóbal de Las Casas es una de las ciudades más antiguas de Chiapas, fundada por Diego de Mazariegos en 1528 con el nombre de Villa Real de Chiapa de los Españoles. En 1848 su nombre fue cambiado por el de San Cristóbal de Las Casas, en homenaje al obispo Bartolomé de Las Casas (ver Trens: 1957, p. 16).

${ }^{4}$ Los países que hacen parte de la denominación genérica de Oriente Medio (o Próximo Oriente y Cercano Oriente), consisten en aquellos países asiáticos que rodean la parte oriental del Mediterráneo: Turquía, Siria, Líbano, Israel, Jordania, Irak, Arabia Saudí, Bahrein, Chipre, Emiratos Árabes Unidos, Irán, Kuwait, Libia, Omán, Qatar, Yemen y Egipto (ver la Enciclopedia Espasa Calpe S. A., 2003: 1273).

${ }^{5}$ Por ejemplo, el famoso texto de Génesis 3.1-7, referente al "pecado original" o la "caída del hombre", no encuentra ningún paralelo en todo el Antiguo Testamento. No se habla más de Adán ni de Eva hasta la época de Jesús o el apóstol Pablo. En el Antiguo Testamento, vemos que para los judíos el pecado es la apostasía, la idolatría. Éste es el problema religioso de fondo, comprendido por los judíos como pecado: la constante lucha entre la fe y los rituales del Dios Javé y el Dios Baal.

${ }^{6}$ Las aleyas, o ayat en árabe, son los versículos de las suras que componen el Corán (Qur'ân), el libro sagrado de los musulmanes. Qur’ân significa "lectura" o "recitación”, y conforme la tradición, fue revelado por Alá al profeta Mahoma durante el mes del Ramadán por medio del ángel Ybril (Gabriel). El Corán está formado por 114 suras o capítulos, y cada una de estas suras está formada por capítulos llamados de aleyas.

${ }^{7}$ Su califato duró diez años y fue durante este tiempo que los musulmanes conquistaron Irán y Egipto.
${ }^{8}$ Los califas ortodoxos son los cuatro califas que sucedieron al profeta Mahoma después de su muerte. El primero fue Abu Bakr, su suegro, padre de su esposa Aixa, y que murió en el año 634 (el año 22 de la hégira, o era musulmana). Abu Bakr fue sucedido por Omar, el segundo califa ortodoxo, también suegro de Mahoma. Murió asesinado en 644 (año 23 de la hégira). Omar fue sucedido por Uzman, el tercer califa ortodoxo, que por su vez fue asesinado en 655 . El cuarto y último califa ortodoxo fue Ali Bnu Ali Talib, primo y yerno del profeta Mahoma. Según Fátima Mernissi, "su reinado se inició con tumultos que desembocarán en una guerra civil y en un sorprendente arbitraje que pondrá fin a su califato y a la 'ortodoxia' del poder político en febrero del año 658 (Ramadán del año 37 de la hégira). El mundo musulmán permanecerá siempre dividido en dos: los shíes (escisionistas), incondicionales de $\mathrm{Ali}$, y los sunníes, que aceptaron el resultado del falso arbitraje y el nombramiento de Muhawiya como califa" (Mernissi, 2002 (1987): 259).

${ }^{9}$ Mis sinceros agradecimientos a Gaspar Morquecho, quien compartió conmigo algunas de las entrevistas que realizó con las mujeres musulmanas de la comunidad musulmana de corriente sufi de San Cristóbal de Las Casas.

${ }^{10}$ María Teresa del Riego, "Van a la Meca indígenas de Chiapas", en Diario Reforma 25 de nov. de 2001.

${ }^{11}$ La marginación y pobreza de las familias indígenas que migran a las ciudades casi no necesita ser comprobada. Sin embargo, me gustaría citar una investigación hecha por Paloma Bonfil Sánchez y Raúl Marcó del Pont Lalli sobre las Mujeres indígenas al final del milenio, en la cual explican, en cuanto a las indígenas en la ciudad, que “... se sabe que los indígenas asentados en las zonas urbanas viven condiciones de pobreza, con frecuencia extrema, y ocupan las posiciones ocupacionales y sociales más bajas, vulnerables y precarias; si bien habría que matizar esta afirmación con los casos de migración exitosa que se registran a veces no sólo de modo individual, sino por sectores..." (1999: 275).

${ }^{12}$ Existen diversas opiniones respecto a la migración indígena hacia San Cristóbal de Las Casas. Algunas se refieren a causas económicas y otras a motivos culturales, como las expulsiones por motivos económico-político-religiosos. Aquí, se privilegiará el segundo motivo, pues va más de encuentro con el carácter de este trabajo. Sin embargo, me parece significativo citar el modo en como Jorge Angulo resume las principales causas de la migración: "continúa el problema de expulsiones 
por conflictos político-religiosos, por conflictos de orden preferentemente político, por invasión de tierras (urbanas y rurales), y por factores diversos en la estrategia de la unidad familiar, como el acceso a la educación, y la condición considerada como fundamental, que es la migración como recurso en la estrategia económica de supervivencia" (Angulo, 1996: 163, citado por Bigmore y Perezgrovas, 2003:16).

${ }^{13}$ El primero y gran cisma en el Islam surge tras la muerte del cuarto califa ortodoxo, Ali, y la toma del poder por Muawiya. Es en esta época que el Islam se divide en sunni (sunníes: los que siguen la suna, la tradición) y shía (los chiíes: disidentes). Según Fátima Mernissi, "la causa de la división, que dio lugar al gran cisma islámico, fue la actitud que había que tener frente a un califa injusto: los sunníes aceptaban a Muawiya, el sucesor de Ali, porque, según ellos, lo más importante era poner fin a la guerra civil" (Mernissi, 2002 (1987): 50). Los shíies pensaban lo contrario, oponiéndose a Muawiya por el hecho de éste no ser el verdadero sucesor de Ali. En este gran cisma, cada una de las dos partes desarrolló una teoría diferente sobre lo político y lo jurídico y se subdividió en otros subgrupos divergentes. ${ }^{14}$ La hégira, o hijrah en árabe, significa emigración, y en el Islam marca el comienzo de la era musulmana, ocasión en que el profeta Mahoma y sus primeros seguidores huyeron de La Meca hacia Medina en el año de 622.

${ }^{15}$ Según Aureliano Pérez Yruela, Emir de la comunidad musulmana sufi de San Cristóbal de Las Casas, los gremios son grupos de personas que bajo un maestro o maestros, producen bienes “bajo el principio del apoyo mutuo". Las personas que forman el gremio también están "interesadas en el desarrollo económico y social de su comunidad” (Documento entregado al DESMI por Aureliano Pérez Yruela, 1995).

${ }^{16}$ Agradezco a Gaspar Morquecho por haberme facilitado el acceso a este documento.

${ }^{17}$ Esto ocurría por medio de los mitos, de los ritos y de los símbolos, que instauraban un orden comprensible en el mundo, separando las realidades en polos sagrados y profanos, puros e impuros. De manera general, en su etimología religión significa religare: re-ligar los seres humanos consigo mismos, con sus semejantes, con el cosmos y el misterio que traspasa estas relaciones.
${ }^{18}$ Considero importante esclarecer que cuando me refiero a "religión", aquí, no lo hago bajo ninguna denominación religiosa, como cristiana, musulmana, judaica, budista, etcétera; como tampoco la considero un fenómeno compartido solamente por personas creyentes en algunas de estas denominaciones. Pienso, más bien, en la religión como un sistema cultural cuyos símbolos, dogmas y principios influyen en las sociedades de modo consciente o inconsciente, como por ejemplo, el símbolo de "Dios" como "dios-padre" elaborado en el cristianismo y judaísmo es comprendido y compartido tanto por creyentes como por no-creyentes como un símbolo ubicado en la esfera de lo sagrado, y que afecta incluso a las personas que no creen en Dios y que tampoco se relacionan con las estructuras religiosas institucionales. Esto es así porque el símbolo (en este caso el símbolo religioso) no depende de la mera aceptación racional, sino que actúa en otros niveles de la psique humana diferentes del nivel racional.

${ }^{19}$ Esta realidad ha posibilitado que las mujeres y los hombres de hoy puedan desempeñar funciones y comportamientos variados, de acuerdo con su contexto social, con su personalidad, posibilidades e interés. A pesar de que en la actualidad, las identidades de género son más flexibles, todavía existen en nuestras sociedades las llamadas desigualdades de género, y la división sexual del trabajo en variados grados y formas.

${ }^{20}$ La shahada significa confesión de fe musulmana, y consiste en la fórmula "no hay otro Dios que Dios y Mahoma es su profeta”. Es el primer pilar del Islam.

${ }^{21}$ Reunión semanal de los musulmanes que se da los viernes por la tarde.

${ }^{22}$ En árabe diker, consiste en una liturgia de rememoración y repetición de los nombres divinos de Alá. En la comunidad musulmana sufi de San Cristóbal, se da los jueves por la noche. ${ }^{23}$ El salat es la oración diaria por medio de la postración, que se hace cinco veces al día en dirección a La Meca.

${ }^{24} \mathrm{El}$ Jajjes uno de los cinco pilares del Islam. Consiste en que toda persona musulmana mayor de edad, si tiene condiciones financieras, vaya al menos una vez en la vida a La Meca. Los otros cuatro pilares del Islam son la shahada, o sea, la confesión de fe, la oración diaria, el salat; el ayuno en el mes del Ramadán y, por fin, el zacat, o sea, la limosna u ofrenda a los pobres. 


\section{Bibliografía}

Abaít Sbah, Fatna, 2000 (1986), La mujer en el inconsciente musulmán, Ediciones del Oriente y del Mediterráneo, Madrid. Agazzi, Evandro, "El desafío de la interdisciplinaridad: dificultades y logros", en Texto oral del Seminario de Profesores impartido en el Departamento de Filosofía de la Universidad de Navarra el 14 marzo 2002 en el marco del proyecto de investigación "Interdisciplinaridad desde la filosofía de la ciencia". Documento impreso.

Angulo, Jorge Ignacio Barredo, 2003, "Procesos de población y organización social en comunidades indígenas de San Cristóbal", en Anuario de Estudios Indígenas IX, Instituto de Estudios Indígenas, Universidad Autónoma de Chiapas, San Cristóbal de Las Casas, pp. 63-81.

Aramoni Calderón, Dolores y Morquecho Escamilla, Gaspar, 1998, "El recurso de las armas en manos de los expulsados de San Juan Chamula", En vV.AA. Chiapas: el factor religioso: un estudio multidisciplinario de las guerras santas de fin de milenio. Tomo II, Revista Académica para el estudio de las religiones, México, pp. 235-291.

Archivo personal de Gaspar Morquecho, 2004.

Berger y Luckmann, Thomas, 1980 (1969), "La sociología de la religión y la sociología del conocimiento". En Roland Robertson, (comp.), Sociología de la religión, Fondo de Cultura Económica, México, pp. 54-64.

Bigmore, Pablo y Perezgrovas Raúl Garza, 2003, "Vida Cotidiana en las colonias indígenas en la zona peri-urbana de San Cristóbal de Las Casas", en Anuario de Estudios Indígenas IX, Instituto de Estudios Indígenas, Universidad Autónoma de Chiapas, San Cristóbal de Las Casas, pp. 13-61.

Cruz Burguete, Jorge Luis, 1998, Identidades en fronteras, fronteras de identidades: la reconstrucción de la identidad étnica entre los chujes de Chiapas, El Colegio de México, Centro de Estudios Sociológicos, México.

Dieterich, Heinz, 2001, Identidad nacionaly globalización: la tercera vía, Nuestro Tiempo, México.

Ederly, Jorge e Lourdes Argüelles, 2002, "La nueva Jihad: percepciones y problemas teóricos", en Islam y la Nueva Jihad, Revista Académica para el Estudio de las Religiones: un análisis interdisciplinario sobre el 11 de septiembre desde América Latina, México, pp.103-150.
Ederly, Jorge e Lourdes Argüelles, 2003, La nueva Jihad: mitosy realidades sobre el pan-islamismo, Publicaciones para el Estudios Científico de las Religiones, México.

Geertz, Clifford, 1991 (1973), La Interpretación de las culturas. Editorial Gedisa S.A., Barcelona.

Giménez, Gilberto, 2000, "Identidades étnicas: estado de la cuestión", en Leticia Reina (coord.), Los retos de la etnicidad en los estados-nación del siglo XXI, Centro de Investigaciones y Estudios Superiores en Antropología Social, Instituto Nacional Indigenista, Miguel Ángel Porrúa, México, pp. 45-70.

Hernández Castillo, Rosalva Aída, 1995, "De la sierra a la selva: identidades étnicas y religiosas en la frontera sur”, en Juan Pedro Viqueira y Mario H. Ruz (editores), Chiapas: los rumbos de otra historia, Universidad de Guadalajara, UNAM, CIESAS, CEMCA, México, pp.407-423.

Lacoste-Dujardin, Camille, 1993, Las madres contra las mujeres: patriarcado y maternidad en el mundo árabe, Ediciones Cátedra, Universitat de Valencia, Instituto de la Mujer, Madrid.

Lara, Marcos Klahr, 2002, “El Islam en Chiapas? El EZLN y el movimiento mundial Murabitum", en Islam y la Nueva Jihad, Revista Académica para el Estudio de las Religiones: un análisis interdisciplinario sobre el 11 de septiembre desde América Latina, México, pp. 79-91.

Marcos, Silvia, 2002, "Lecturas alternativas del Corán: hacia una hermenéutica feminista del Islam”, en Islam y la Nueva Jihad, Revista Académica para el Estudio de las Religiones: un análisis interdisciplinario sobre el11 de septiembre desde América Latina, México, pp. 50-66.

Masferrer, Elio Kan, 2002, "Integrismo islámico y contexto socio-histórico: los factores etnorreligiosos en los procesos políticos post-coloniales", en Islam y la Nueva Jihad, Revista Académica para el Estudio de las Religiones: un análisis interdisciplinario sobre el 11 de septiembre desde América Latina, México, pp. 31-50. Mernissi, Fátima, 2002 (1987), El harén político: el Profeta y las mujeres, Ediciones del Oriente y del Mediterráneo, Madrid.

—, 2003 (1992), El miedo a la democracia: Islam y democracia, Ediciones del Oriente y del Mediterráneo, Madrid.

—, 2000, Marruecos a través de sus mujeres, Ediciones del Oriente y del Mediterráneo, Madrid.

Rivera Farfán, Carolina, 1998, "La diáspora religiosa en Chiapas: notas para su estudio”, en VV.AA. Chiapas: el factor religioso: un estudios multidisciplinario de las guerras santas de fin de milenio. Tomo 
II, Revista Académica para el estudio de las religiones, México, pp. 173-188.

Scott, Joan W, 2000, El género: una categoría útil para el análisis histórico, en Lamas, Marta (comp. e intr.). El género: la construcción cultural de la diferencia sexual, PUEG, México.
Sociedad Bíblica Católica Internacional, 1995, La Biblia Latinoamericana: edición pastoral, Editorial Verbo Divino y San Pablo, 36a edición revisada, Madrid.

Trens, Manuel B, 1957, Bosquejos históricos de San Cristóbal de Las Casas, s/f, México. 